\title{
Reformalización en la mira de la congruencia
}

\author{
Reformalization under the consistency principle
}

Rodrigo Andrés Guerra Espinosa ${ }^{1^{*}}$

Universidad de los Andes, Santiago, Chile

rguerra@uandes.cl

https://orcid.org/0000-0003-2540-8814

\begin{abstract}
RESUMEN: En relación con la reformalización, introducida en el Derecho procesal penal mediante las practicas del Ministerio Público, el autor se hace cargo de la situación jurídica de este fenómeno en el sistema chileno, en el contexto del principio de congruencia. Luego de confirmar la interpretación legal desde la cual se autoriza su uso y de presentarse las sentencias disponibles en la materia, se propone un análisis crítico de la reformalización.
\end{abstract}

Palabras clave: Principio de congruencia; reformalización; garantías fundamentales.

ABSTRACT: In relation to the reformalization, introduced in the criminal procedural law through the practices of the Public Prosecutor's Office, the author deals with the legal situation of this phenomenon in the Chilean system, in the context of the principle of congruence. After confirming the legal interpretation from which its use is authorized and presenting the available sentences on the matter, a critical analysis of reformalization is proposed.

KEYwORDs: Congruency principle; reformalization; fundamental rights.

SUMARIO: Introducción; 1. Plataforma conceptual del principio de

1 Doctor en Derecho, Profesor de Derecho Penal de la Universidad de los Andes, Chile. Dirección postal: Facultad de Derecho, Universidad de los Andes, Monseñor Álvaro de Portillo 12.455, Las Condes, Santiago, Chile. Abogado. Este proyecto es resultado de un artículo monográfico realizado en el marco del proyecto FONDECYT iniciación 11190024 titulado "Delimitación del miedo insuperable ante el estado de necesidad". 
congruencia; 2. Reformalización: análisis crítico y alcances de la figura; 3. Méritos y defectos de la reformalización; Conclusiones; Bibliografía.

\section{INTRODUCCIÓN}

Por medio de la reformalización se introducen diferentes consecuencias para el principio de congruencia ${ }^{2}$, dando lugar a una serie de problemáticas interpretativas en el sistema chileno. Este artículo tiene por finalidad hacerse cargo de algunas de estas, concretamente la que suscita la reformalización en el derecho de defensa ${ }^{3}$, esto es, aquella

2 En este contexto, utilizamos la expresión congruencia y no correlación para denominar la falta de relación que existe entre los presupuestos fácticos de acusación y la formalización de la investigación en proceso penal chileno. Toda variación o incorporación de nuevos hechos no comunicada en la fase de investigación, debe ser rechazada en los presupuestos de la acusación. De lo contrario, estaríamos infringiendo la congruencia consagrada entre estos presupuestos fácticos en el art. 259 inciso final del Código Procesal Penal, FALCONE SALAS, Diego. Apuntes sobre la formalización de la investigación desde la perspectiva del objeto del proceso penal, p. 211. Si bien la expresión congruencia se observa en el trabajo de diversos autores chilenos, debemos indicar que en otros se utiliza la expresión deber de correlación, véase DEL RÍO FERRETTI, Carlos. Los poderes de decisión del juez penal: Principio acusatorio y determinadas garantías procesales (el deber de correlación), passim. Sin embargo, hemos optado por la expresión congruencia para lograr conexión con la jurisprudencia chilena. Así, esta denomina este vicio principio de congruencia, véase, a modo de ejemplo, la Sentencia de la Corte de Apelaciones de Antofagasta, resolución de 27 de octubre de 2008, Rol 238-2008, considerando quinto.

3 El principio de congruencia está estrechamente conectado con el derecho a defensa. El principio de congruencia no descansa en un mero deber de correlación fáctica entre la formalización y la acusación. El reconocimiento de un mero deber de correlación en el principio acusatorio nos desvía de las aportaciones de la congruencia en el contexto de "la separación de la función de acusación de la de enjuiciamiento, funciones que deben ser atribuidas a órganos distintos, y por tal motivo la acusación -el objeto del proceso- [que] ha de ser planteada en juicio por un sujeto distinto del juez", véase RODRÍGUEZ VEGA, Manuel. Sistema acusatorio de justicia penal y principio de obligatoriedad de la acción penal, pp. 646 y ss. De ahí que tenga relevancia en una línea teleológica objetiva destacar la vinculación del principio de congruencia con el derecho a defensa en el proceso. La formalización es una garantía para el 
comunicación de la investigación de uno o más hechos al imputado que, posiblemente constitutivos de algún delito, tiene lugar con posterioridad a la formalización ${ }^{4}$. En este contexto, no se tratarán otras materias de relevancia como, por ejemplo, los efectos del principio de congruencia en materia de nulidad ${ }^{5}$, entre otras.

Sin embargo, cabe subrayar que la jurisprudencia exhibe la relevancia del principio de congruencia, como la falta de conexión entre los hechos de la formalización, la acusación y la sentencia ${ }^{6}$. Esto explica el estudio preferente que aquí entregamos a la reformalización,

imputado que puede dar lugar a escenarios más o menos favorables. Por ello, es importante destacar que la reformalización no solo infringe en términos generales el principio acusatorio sino específicamente el derecho a defensa.

4 En este contexto, el legislador define en el art. 229 del CPP la formalización en los siguientes términos: la formalización de la investigación es la comunicación que el fiscal efectúa al imputado, en presencia del juez de garantía, de que desarrolla actualmente una investigación en su contra respecto de uno o más delitos determinado.

5 En esta línea, la relación fáctica de los hechos debe existir entre la formalización, la acusación y la sentencia, señalados en los artículos 229, 259, 341 y garantizados con la nulidad del juicio según el art. 374 letra f) del CPP. El principio de congruencia constituye una regla de razonamiento fundamental para la dogmática procesal penal. Si bien su estudio se limita generalmente a tratados y manuales de Derecho procesal penal, con la inserción del sistema acusatorio en Chile, el principio es estudiado en la actualidad, véase ARIAS, Cristián. El artículo 360 del Código procesal penal, 2007, p. 154 y ss.

6 En este orden de ideas, la Sentencias de la Corte de Apelaciones de Copiapó, en causa Rol N ${ }^{\circ} 248-2012$, indica que el principio de congruencia o de correlación entre la imputación y el fallo está consagrado legislativamente en el art. 341 del CPP. Así pues, la sentencia condenatoria no podrá exceder el contenido de la acusación. En consecuencia, no se podrá condenar por hechos o circunstancias no contenidos en ella. En esta línea, según el razonamiento de la Corte, "el principio de congruencia supone, entonces, conformidad, concordancia o correspondencia entre la determinación fáctica del fallo con relación a los hechos y circunstancias penalmente relevantes que han sido objeto de la imputación contenida en la acusación, en términos detallados de tiempo, lugar y modo de comisión que fueren de importancia para su calificación jurídica". Si bien algunos autores sostienen que la limitación de la acusación a la sentencia es manifestación del principio acusatorio, debemos indicar que nuestro trabajo estudia los rendimientos del principio de congruencias en el ejercicio de causales de impugnación. El principio acusatorio es reflejo de un mandato de optimización que debemos diferenciar del sistema acusatorio, RODRÍGUEZ VEGA, Manuel. Sistema acusatorio de justicia penal y principio de obligatoriedad de la acción penal, pp. 646 y ss. 
sin menoscabo de esta omisión a la congruencia, en lo que concierne a la nulidad, que si bien no conoce casos en que se haya aplicado en torno a la reformalización, nos parece el asunto más interesante para estos efectos.

Así las cosas, la reformalización tiene importancia porque pone a prueba los límites de la formalización como garantía en el proceso. De ahí que parezca pertinente, antes de abordar el análisis de la legislación chilena, hacerse cargo de la ausencia de regulación de la reformalización, en la que las importantes cuestiones se pueden apreciar, con lo cual se obtiene un panorama general que permite apreciar los cambios en la jurisprudencia, así como los méritos y defectos de la reformalización.

\section{Plataforma conceptual del principio de congruencia}

Hasta el uso del principio de congruencia en la jurisprudencia, la regulación positiva obligaba a considerar la estrecha relación entre los presupuestos de la acusación y los de la sentencia, básicamente una conexión destinada a la protección de la defensa del imputado, de forma de no vulnerar el debido proceso. Ahora bien, en la medida en que tales presupuestos exhiban estructuras diferenciadas (acusación y juicio), no sería posible un examen conjunto.

Para estos efectos se pueden distinguir tres aristas esenciales en el principio de congruencia: la manifestación del derecho de defensa, la relación circunstanciada y precisa de los hechos atribuidos en la acusación y el establecimiento de un contenido dogmático para cautelar la presunción de inocencia. De este modo, a continuación, se revisará sucintamente estos aspectos del principio.

En cuanto a la llamada reformalización, en la medida en que su uso no ponga en riesgo el sistema acusatorio, debe descartarse de plano su consagración en el art. 229 del CPP. Así, admitir la reformalización permite incorporar nuevos hechos que en el proceso podrían ir en favor del imputado. Sin embargo, esta última hipótesis no es del todo evidente, pues la subsunción de los hechos - en una figura delictiva más lesiva- fracasaría en la medida en que la reformalización busque definir debidamente los contornos del suceso. 
En lo que concierne a la reformalización, desde luego esta podría tener aplicación en favor del reo, pues podría permitir incorporar nuevos presupuestos fácticos en virtud del principio de objetividad ${ }^{7}$. Sin embargo, no es posible observar en la reformalización una restricción de operatividad en favor del imputado ${ }^{8}$. De ahí que su uso puede implicar un desequilibro en el proceso en favor del órgano persecutor ${ }^{9}$. De esta forma, hasta que no impere una concepción restringida de la reformalización, este instrumento parece distorsionar el sentido de la formalización.

\subsection{PRINCIPIO de CONGRUENCIA COMO MANIFESTACIÓN DEL DERECHO DE DEFENSA}

De las tres aristas enunciadas en torno a los fundamentos del principio de congruencia, el de este como una manifestación del derecho de defensa es una de las de mayor importancia ${ }^{10}$, por su atractivo en resultados de absolución y de menor riesgo en comparación con otras defensas, especialmente propias de la inexigibilidad ${ }^{11}$. Así, el desarrollo

7 En este contexto, la disposición del art. 77 del CPP indica que los fiscales ejercerán y sustentarán la acción penal pública en la forma prevista por la ley. Con ese propósito practicarán todas las diligencias que fueren conducentes al éxito de la investigación y dirigirán la actuación de la policía, con estricta sujeción al principio de objetividad consagrado en la Ley Orgánica Constitucional del Ministerio Público.

8 Sin embargo, a modo de ejemplo, se puede observar restricciones en favor del imputado en la disposición del art. 334 del CPP. Esta disposición indica de forma expresa que no se podrá incorporar o invocar como medios de prueba ni dar lectura durante el juicio oral, a los registros y demás documentos que dieren cuenta de diligencias o actuaciones realizadas por la policía o el ministerio público. Sin embargo, jurisprudencialmente se asienta la excepción cuando esta prueba pueda ser beneficiosa para el imputado, véase BLANCO, Rafael. Código Procesal Penal: Sistematizado con jurisprudencia, 2017.

9 Respecto del principio de igualdad en el proceso, véase GANDULFO R. Eduardo. Principios del derecho procesal penal en el nuevo sistema de procedimiento chileno. Revista de Derecho de la Universidad Católica de Valparaíso. Valparaíso, 1999, p. 449.

10 Véase ARIAS, Cristián. El artículo 360 del Código procesal penal. Santiago, 2007, p. 154 - 174.

11 Respecto de la problemática de dónde circunscribir el principio de inexigibilidad en el sistema chileno, véase GUERRA, Rodrigo. Estado de necesidad como conflicto de intereses: una propuesta de interpretación desde la inevitabilidad. Santiago: Ara Editores, p. 97 y p. 97 nota 228. 
ulterior del principio - en fallos de nulidad- explica que las primeras reflexiones se hayan fundado a su razón frente a la incongruencia de presupuestos fácticos.

Como se ha indicado, el principio de congruencia obliga a reparar en la relación circunstanciada de los hechos objeto de la formalización. Esto es, la comunicación de uno o más presupuestos que posiblemente sean constitutivos de delito. Sin embargo, la redacción del precepto del art. 230 del CPP confunde en la materia, pues se desprende jurisprudencialmente que no existe una restricción estricta en torno a la oportunidad de formalización. De este modo, la posibilidad de reformalizar estaría aparentemente permitida en el proceso ${ }^{12}$.

La formalización es resultado de una de las garantías más importantes del imputado no así, como se indicará, en la segunda sección de este artículo, la figura de reformalización que, en cuanto tal, debe estar cubierta por los parámetros del debido proceso. Garantiza esta conclusión preliminar, en primer lugar, la circunstancia de tratarse de una formulación fáctica de cargos que condiciona la estrategia de defensa.

Así las cosas, por manifestación del derecho a defensa debe entenderse el conocimiento estricto de los hechos que se imputan ${ }^{13}$. Nada sugiere que se deba adoptar una exégesis distinta de la que opera en la formalización y la acusación, como ocurre en los arts. 229 CPP (formalización), 259 CPP (acusación) y 341 CPP (sentencia), disposiciones que jamás han entregado una exegesis diferente de la que gobierna en la letra f) del art. $374 \mathrm{del} \mathrm{CPP}{ }^{14}$.

12 Así las cosas, el art. 230 del CPP indica que el fiscal podrá formalizar la investigación cuando considerare oportuno formalizar el procedimiento por medio de la intervención judicial.

${ }_{13}$ En este orden de ideas, el principio de congruencia es una consecuencia del derecho a defensa. Pues bien, únicamente existe defensa ante una formulación precisa de los hechos. Es decir, una formulación que imputado conozca y pueda cuestionar. De ahí que únicamente sobre estos hechos el Tribunal pueda pronunciarse, véase FLEMING, Abel; LÓPEZ VIÑALS, Pablo. Garantías del Imputado. Buenos Aires: Rubinzal-Culzoni Editores, 1a Edición, 2007, p. 513.

14 En este orden de ideas, la disposición de la letra f) del art. 374 nos indica que será motivo de nulidad la sentencia se hubiere dictado con infracción de lo prescrito en el artículo 341 del CPP. Asimismo, a modo de ejemplo, la Sentencia de la Corte de Apelaciones de Arica, Rol 25-2010, indica, en su considerando tercero, "que, la exigencia legal de congruencia no es sino un reflejo del 
Lo relevante es que, de aceptarse dicha congruencia, es decir, no solo entre los hechos de la acusación y la sentencia, debería admitirse que una imprecisión en los hechos de la formalización podría dar lugar a la nulidad del juicio. Así, a modo de ejemplo, cuando la fiscalía incorpora presupuestos facticos que enmiendan la omisión de algunos, se asume como posible un resultado menos favorable a la situación del imputado. Pues bien, el Ministerio Público podría incorporar hechos que aumentan el desvalor de la hipótesis delictiva ${ }^{15}$.

Finalmente, sin perjuicio de las objeciones que puedan dirigir a la lectura presentada en torno al principio de congruencia, como manifestación del derecho de defensa, debe examinarse si resuelve adecuadamente la situación que genera la reformalización en el sistema chileno.

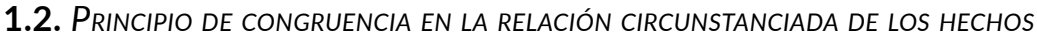

El principio de congruencia se manifiesta en la relación circunstanciada de hechos de la formalización, la acusación y la sentencia

derecho de defensa en cuanto se requiere que la imputación sea precisa y determinada. Así entonces, el tribunal debe cautelar la identidad del objeto del proceso, tanto material, referido a los mismos hechos y circunstancias, como personal, esto es, mismos acusados. De lo anterior no cabe sino concluir que para que el imputado pueda defenderse y ser defendido adecuadamente resulta indispensable saber exactamente cuáles son los hechos que se le imputan, sus circunstancias y calificación. Dicho así, la secuencia lógica y necesaria que todo juicio debe seguir, desde el punto de vista de la congruencia y precisión de la imputación, refiere a que los hechos e imputados de la formalización deben abarcar los hechos e imputados de la acusación; y los hechos y acusados de la acusación deben abarcar los hechos y acusados condenados en la sentencia definitiva. De lo dicho, se desprende que no cualquier error fáctico o circunstancia secundaria de la acusación puede importar una infracción a su congruencia con el fallo, como contrariamente lo sostuvo la defensa al referir a la dicotomía de fechas antes mencionada y han seguido erradamente los jueces de fondo en su ponencia sobre el punto, por cuanto para que ello ocurra es necesario que se establezcan en la sentencia, como delito, hechos que no han sido materia de la acusación, lo que en la especie no ha ocurrido, conforme se desprende de su lectura, en que aparece que los hechos son los mismos".

15 Respecto de una comprensión moderna y racional del desvalor en materia penal, véase SANCINETTI. El disvalor de acción como fundamento de una dogmática jurídico-penal racional. Barcelona: InDret Penal, 2017, p. 1-21. 
condenatoria. Relación que se ve afectada a través de la introducción de nuevos presupuestos que perturban el objeto del proceso ${ }^{16}$. La incorporación de estos hechos produce un detrimento en las garantías del imputado, por medio de la extensión de la competencia del Tribunal a cuestiones ajenas a su jurisdicción ${ }^{17}$. Tal situación procesal, en el sistema jurídico penal chileno, ocasiona una infracción de las garantías, que sería susceptible de recurso de nulidad o cautela de garantía ${ }^{18}$.

16 En este orden de ideas, “dentro de esta concepción del acusatorio, la doctrina había entendido que el objeto del proceso se estructuraba e individualizaba con base en dos criterios: uno subjetivo y el otro objetivo. El objeto del proceso se identificaba y diferenciaba de los otros posibles objetos por referencia al sujeto pasivo o imputado-acusado en contra del cual se dirige el proceso penal,5 lo que se denomina la identidad subjetiva del objeto del proceso. De otra parte, el objeto del proceso se identifica por el hecho punible (o hechos) atribuido a ese sujeto, lo que da lugar a la identidad objetiva del mismo", DEL RÍO FERRETI, Carlos. 2009, p. 205. En esta línea, Binder indica que la precisión y la claridad de la acusación son muy importantes porque es la acusación la que fija el objeto del juicio, de los hechos que hacen la acusación. Subsidiariamente está fijado por la calificación jurídica que propone la acusación, véase BINDER, Alberto M. B. 1999, p. 162. Los términos del art. 10 del código procesal penal.

17 En esta línea, Binder indica que la precisión y la claridad de la acusación son muy importantes porque es la acusación la que fija el objeto del juicio, de los hechos que hacen la acusación. Subsidiariamente está fijado por la calificación jurídica que propone la acusación, véase BINDER, Alberto M. Introducción al Derecho Procesal Penal, 1999, p. 162.

Así pues, el art. 10 del CPP dispone que, respecto de la cautela de garantías, en cualquiera etapa del procedimiento en que el juez de garantía estimare que el imputado no está en condiciones de ejercer los derechos que le otorgan las garantías judiciales consagradas en la Constitución Política, en las leyes o en los tratados internacionales ratificados por Chile y que se encuentren vigentes, adoptará, de oficio o a petición de parte, las medidas necesarias para permitir dicho ejercicio.___ Si esas medidas no fueren suficientes para evitar que pudiere producirse una afectación sustancial de los derechos del imputado, el juez ordenará la suspensión del procedimiento por el menor tiempo posible y citará a los intervinientes a una audiencia que se celebrará con los que asistan. Con el mérito de los antecedentes reunidos y de lo que en dicha audiencia se expusiere, resolverá la continuación del procedimiento o decretará el sobreseimiento temporal del mismo._Con todo, no podrá entenderse que existe afectación sustancial de los derechos del imputado cuando se acredite, por el Ministerio Público o el abogado querellante, que la suspensión del procedimiento solicitada por el imputado o su abogado sólo persigue dilatar el proceso. 
Diferentes casos reflejan la infracción del principio de congruencia, como el presentar en juicio prueba que no tiene relación con los hechos de la acusación; el caso de quien es condenado por hechos que no se encuentran en la acusación; el aceptar incorporar prueba de la fiscalía que, en la audiencia de preparación de juicio oral, no tiene concordancia con los hechos de la acusación, entre otros supuestos. De ahí que la práctica procesal de la reformalización sea una problemática adecuada en este trabajo, con el propósito de ilustrar por qué la reformalización puede afectar el principio de congruencia ${ }^{19}$.

Conforme a lo expuesto, la incorporación de un nuevo hecho no es indiferente en el proceso, pues existe consecuencias en términos de imputación. Por esta razón, el principio de congruencia nos parece que cobra relevancia dentro de la doctrina de la imputación, para la que existen ciertos hechos que, concurriendo determinados factores de control, es necesario enunciar ${ }^{20}$. Así, si los hechos imputados fueran indeterminados sería siempre posible imputarlos bajo parámetros que

19 Si la defensa conoce de los hechos imputados a su cliente por medio de la formalización, prepara su teoría del caso en atención a estos. En este sentido, siguiendo a Moreno la teoría del caso puede ser definida como "el conjunto de actividades estratégicas que debe desarrollar un litigante frente a un caso, que le permitirá determinar la versión de los hechos que sostendrá ante un tribunal, y la manera más eficiente y eficaz de presentar persuasivamente, las argumentaciones y evidencias que acreditan en un juicio oral", MORENO HOLMAN, Leonardo. Teoría del Caso, 2014, p. 18.

20 En este sentido, la imputación fáctica debe considerarse tanto en la teoría del caso de la fiscalía como la defensa. Presentación de los hechos que incide en el juicio de imputación fáctico que realiza el juez. Por ello, una adecuada teoría del caso puede generar una apreciación de los hechos que afecte la valoración de la realidad fáctica del caso, porque esta solo tendría un carácter formal, véase BLANCO, Rafael; DECAP, Mauricio; MORENO, Leonardo; ROJAS, Hugo. Litigación estratégica en el nuevo proceso penal, 2005, p. 1537. En la misma línea, podemos sostener que esta variación en la realidad fáctica del caso se podrá relativizar por su aplicación concreta. Pues en "todo contexto de conocimiento científico y empírico, incluido el de procesos judiciales, la verdad es relativa", TARUFFO, Michele. La Prueba, 2008, p. 26. En cambio, en modelos procesales de carácter inquisitivo "rige el principio de investigación, también llamado principio de la verdad material o principio de instrucción o inquisitivo [que] supone que el tribunal investiga por sí mismo los hechos de la causa ('instruye' por sí mismo) y, en ello, no está vinculado a los requerimientos y declaraciones de las partes del proceso", ROXIN, Claus. Derecho procesal penal, 2001, p. 99. 
van más allá de lo extraordinario ${ }^{21}$, mientras que si esos mismos son acuciosamente descritos en la formalización solo serán imputables en mérito de una razón proporcionada ${ }^{22}$.

El principio de congruencia no debe entenderse, entonces, como una regla que establece las condiciones de admisibilidad de nuevos hechos en el proceso. Pues bien, de lo contrario, en diversas oportunidades sería valido introducirlos por medio de la reformalización. Por ejemplo, un fiscal podría incorporar nuevos hechos, cuando ello sea necesario en la pesquisa de un delito de alta complejidad; un fiscal podría incorporar nuevos presupuestos para fortalecer su teoría del caso; un fiscal podría presentar un hecho omitido en la formalización cerrado el plazo de investigación; y un fiscal podría modificar la relación circunstanciada de los hechos para evitar que se propague una comprensión inadecuada de la imputación fáctica ${ }^{23}$.

Ninguno de estos casos establece una excepción al principio de congruencia. Por ello, puede sostenerse que el principio de congruencia está subordinado a la formalización. Así pues, requiere de un razonamiento supeditado a un supuesto conceptual acerca de qué hechos sería adecuado considerar objeto del proceso. En otras palabras, nos parece que el principio está conectado con la formalización a modo de garantía, es decir, como un mecanismo de defensa que requiere precisión en hechos

${ }^{21}$ Respecto de los parámetros de la imputación extraordinaria, véase HRUSCHKA, Joachim. Imputación y derecho penal. Navarra, 2005.

${ }^{22}$ En este contexto, la palabra proporción es utilizada dentro del contexto de aquellos principios que sirven de base para una política criminal. Así las cosas, el principio de seguridad y legalidad exigen una formulación precisa de los cargos que debe estar en consonancia con el principio de la dignidad humana. Así las cosas, existirían metarreglas que aludirían "a criterios operativos para casos de conflicto entre principios ... [para] llegar a las concretas reglas que resuelven grupos de casos. No se trataría propiamente de reglas que han surgido de la ponderación de principios, sino de enunciados (criterios) sobre la operatividad de esos principios y la prevalencia de unas sobre otras. La denominación [...] más adecuada es la de metarreglas, para destacar que son enunciados normativos y, además, de segundo orden o referidas a otros", SÁNCHEZ-OSTIZ, Pablo. Fundamentos de Política criminal. Madrid: Marcial Pons, 202, p. 80.

${ }^{23}$ SÁNCHEZ-OSTIZ, Pablo. La libertad del derecho penal. Barcelona: Atelier, 2014, p. 38. 
que, inicialmente, no deberían ser modificados ${ }^{24}$. De ahí que, incluso, el mismo imputado pueda ser informado de los hechos si se considera afectado por una investigación no formalizada ${ }^{25}$.

Una vez que se ha determinado la importancia de la formalización como garantía en el proceso, el principio entra en escena diciéndonos que hechos no pueden ser incorporados como objeto del proceso en la resolución de un conflicto intersubjetivo ${ }^{26}$. Así, cuando la relación circunstanciada de los hechos satisface las exigencias del principio de congruencia, el agente goza de las garantías del debido proceso.

El principio de congruencia opera, pues, como una parte fundamental de los presupuestos de la imputación, ya que los hechos constituyen el factum del proceso. Tal consecuencia precede a definir la

${ }^{24}$ Si bien es posible reconocer una vinculación entre el contenido de la formalización y la acusación en relación con el principio de delimitación progresiva del objeto del proceso, es importante indicar que la cuestión no está zanjada en términos dogmáticos. Pues el objeto del proceso puede observarse tanto en la calificación jurídica de los hechos como en los presupuestos fácticos de la acusación e incluso la formalización. En este contexto, según el aforismo Iura Novit Curia, los hechos pueden ser objeto de discusión en su calificación jurídica y el tribunal tiene autonomía sobre esta calificación y preliminarmente en la audiencia de control detención (ostensibilidad de los indicios que acreditan los presupuestos fácticos de la prisión preventiva). Sin embargo, en el plano constitucional penal la congruencia es parte de una tutela judicial efectiva. De ahí que la falta de congruencia en los hechos afecte la garantía de defensa en juicio. Por ello, la congruencia impide la alteración de los hechos que son fijados en el objeto del proceso según la perspectiva de este trabajo. Cuestión que, si bien no tiene tratamiento dogmático expreso a propósito de la formalización, se puede observar el plano procesal constitucional en AGUIRREZABAL GRÜNSTEIN, Maite. La congruencia procesal como límite del principio dispositivo en el proceso civil, p. 510.

25 Así, en lo que respecta al control judicial anterior a la formalización de la investigación, según lo dispuesto en el art. 186 del CPP, cualquier persona que se considerare afectada por una investigación que no se hubiere formalizado judicialmente, podrá pedir al juez de garantía que le ordene al fiscal informar acerca de los hechos que fueren objeto de ella. También podrá el juez fijarle un plazo para que formalice la investigación.

26 Respecto a la realidad intersubjetiva del Derecho penal, véase SILVA SÁNCHEZ, Jesús María. Perspectivas sobre la política criminal moderna. Buenos Aires: Editorial ábaco de Rodolfo Depalma, 1998, p. 44. 
atribución de responsabilidad en el segundo nivel de la imputación ${ }^{27}$. Por eso el principio de congruencia es un filtro que nos permite identificar sobre qué versará la discusión de los dos niveles de la imputación, porque el principio no incide en el mérito o demerito de los antecedentes presentados, sino en los presupuestos fácticos que se presenta ante el tribunal.

Por último, nos parece que el principio de congruencia puede operar en una perspectiva formal y material. Cuando opera en la perspectiva formal, constituye una guía para la deliberación de la formalización en casos en los que se prevé que la incorporación de un nuevo hecho conduce a un efecto nocivo en la defensa del imputado. Cuando opera en la perspectiva material, constituye un criterio para el juzgador sobre la identidad material del proceso, que es el contenido hipotético normativo del crimen, simple delito o falta en el proceso, sin embargo, a diferencia de la perspectiva formal, el juzgador tendrá en cuenta no solo los efectos jurídicos de estos nuevos hechos en miras a la nulidad, sino también los que debió prever de no valorar en juicio.

\subsection{CONTENIDO DOGMÁtICO DEL PRINCIPIO DE CONGRUENCIA}

Hemos observado que, al estudiar el principio de congruencia, el modelo chileno presenta una aceptación general. Así, la expresión delitos determinados del art. 229 del CPP en torno a la formalización, nos entrega el derecho a reconocer los hechos precisos que se investigan en la audiencia de control de detención y su relación circunstanciada. Por eso, esta relación debe indicar el día, lugar, hora y fecha de ocurrencia de los hechos. La legislación chilena precisa este punto a través de los factores esenciales de la conducta imputada. Último punto que, ciertamente, se ratifica a través de la expresión cargos que se presentaren en el art. 232 del CPP.

27 La imputación de segundo nivel es jurídica. En este nivel de la imputación se debe acreditar que el sujeto sabiendo que infringe la norma no ajusta su comportamiento a esta. Así pues, sin adolecer alguna afectación en sus capacidades psicobiológicas de comprensión o alguna hipótesis de vis compulsiva, opta por infringir el ordenamiento fuera de una hipótesis de error de prohibición, véase HRUSCHKA, Joachim. Imputación y Derecho penal. Navarra: Editorial Aranzadi, 2005, p. 38; SÁNCHEZ-OSTIZ, Pablo. La libertas del derecho penal. Barcelona: Atelier, 2014, pp. 66-73. 
Pero estas razones, se nos presenta como insuficiente la interpretación entregada en torno a la congruencia. En efecto, esta apunta a que la base del principio está compuesta por la inviolabilidad del derecho a defensa. De ahí que todo aquello que, en la sentencia, implique una sorpresa para quien se defiende, en la línea de un nuevo antecedente fáctico lesiona la congruencia ${ }^{28}$. Si estas explicaciones se ordenan a este último punto, entonces nos parece que la congruencia logra su objetivo.

La pregunta por la congruencia es la pregunta por la justificación de su distinción central: aquella que existe en la relación de los hechos de la formalización, la acusación y la sentencia. Así, no puede plantearse sobre la base de una identidad meramente semántica. De ahí que se deba mostrar cuál es la razón de que un nuevo hecho sea parte del proceso. En otras palabras, hay que demostrar por qué es deseable para la defensa, sin importar su trascendencia en la pretensión del ente persecutor.

Ahora bien, el argumento positivo para aceptar que la sentencia no puede exceder el contenido de la acusación se encuentra en el art. 341 del CPP. En efecto, si tal disposición se dirige a evitar condenas por hechos no contemplados en la acusación, únicamente puede recaer la diferencia entre la acusación y la sentencia en la calificación jurídica de los hechos, o la concurrencia de causales modificatorias agravantes de la responsabilidad penal no incluidas en la acusación.

Que la calificación jurídica de un tribunal afecte las pretensiones del Ministerio Público o la defensa, puede ser emendada por la posibilidad de someter a cuestionamiento la tesis del Tribunal. Todas las calificaciones jurídicas conllevan efectos que inciden en la valoración del hecho conforme a la norma ${ }^{29}$. De ahí que no pueda existir una imposición en los parámetros

28 MAIER, Julio. Derecho Procesal Penal, Tomo I, Fundamentos. Buenos Aires: Editores del Puerto S.R.L, 2004, p. 568.

29 Así pues, con posterioridad a la imputación fáctica existe una segunda etapa dirigida a orientar estos hechos por medio de un juicio atingente a las reglas de conducta (applicatio legis ad factum) y de imputación de segundo orden (imputatio iuris). Juicio en que intervienen valoraciones donde cobra relevancia la operación de medición del hecho conforme a una regla de conducta permisiva, prescriptiva o prohibitiva, véase SÁNCHEZ-OSTIZ, Pablo. La libertad del derecho penal. Barcelona: Atelier, 2014, p. 66-73. 
de la calificación, pues puede ser sometidas a control en audiencia ${ }^{30}$. Pero, en realidad, ni siquiera el recurso de nulidad sería una solución al problema en caso de disentir en torno a la calificación jurídica, porque la precisión de los hechos de la acusación es importante en relación con el objeto del proceso $^{31}$. En síntesis, el conocer los hechos de la imputación, la relación circunstanciada de los hechos y las limitaciones propias de esta descripción, nos llevan a aceptar la importancia del principio de congruencia ${ }^{32}$.

\subsection{Conclusiones PROVISIONALES}

El principio de congruencia, como regla procesal que comprende la coherencia de los hechos de la formalización, la acusación y la sentencia, es un principio de razonamiento que provee presupuestos adecuados para imputar responsabilidad. Aunque ha sido estudiado como un principio procesal, es apto para ser acogido en el Derecho penal. En efecto, sin perjuicio de que la congruencia abarca un espectro dogmático de segundo orden en la imputación, el Derecho penal también debe hacer frente a situaciones en las que un agente sea castigado por hechos que están desvinculados de la acusación. Si bien el principio puede ser de ayuda en la deliberación jurídico-penal, nuestra propuesta es que debería ser estudiado en el ámbito de la reformalización, puesto que, confrontado con otras distinciones de la doctrina procesal, el principio aporta soluciones consistentes según observaremos a continuación.

30 En este sentido, según lo dispuesto en el art. 341 del CPP, la sentencia condenatoria no podrá exceder el contenido de la acusación. En consecuencia, no se podrá condenar por hechos o circunstancias no contenidos en ella. Con todo, el tribunal podrá dar al hecho una calificación jurídica distinta de aquella contenida en la acusación o apreciar la concurrencia de causales modificatorias agravantes de la responsabilidad penal no incluidas en ella, siempre que hubiere advertido a los intervinientes durante la audiencia.

31 BINDER, Alberto M. Introducción al Derecho Procesal Penal. Buenos Aires: Editorial Ad-hoc, 1999, p. 162.

32 HORACIO LANGEVIN, Julián. Nuevas Formulaciones del Principio de Congruencia: Correlación entre Acusación, Defensa y Sentencia. Buenos Aires: Fabián J. Di Plácido Editor, 2007, p. 47 


\section{ReformalizACIÓN: ANÁLISIS CRÍtICO Y ALCANCES DE LA FIGURA}

\subsection{INICIOS DE LA REFORMALIZACIÓN}

Luego del inicio de la reforma procesal penal, se introduce la reformalización, cuya existencia en nuestra jurisprudencia altera el escenario en materia de formalización. La reformalización nunca fue objeto de discusión en la reforma procesal penal, de modo que, consecuentemente, el legislador no tuvo en cuenta esta práctica en las decisiones que adoptó en la regulación de la formalización. No debe extrañar entonces que la historia de la formalización no aporte elementos que prueben su existencia.

En efecto, una de las Sentencias de la Corte de Apelaciones de Santiago que le dio origen, en causa Rol 738-2006, del 23 de mayo de 2006, únicamente perseguía limitar la extensión de la formalización por hechos que un principio fueron calificados propios de un robo por sorpresa para recalificarlos como robo con violencia ${ }^{33}$. La única disposición penal prevista, consistente en la formalización de la investigación, se hacía cargo precisamente de la comunicación precisa de los hechos objeto del proceso. Sin embargo, no abordaba la incorporación de nuevos presupuestos a continuación de la formalización.

Luego de que la Corte de Apelaciones de Santiago el 23 de mayo de 2006 aceptara la reformalización - e innovará en este aspecto- se estandariza su uso en la jurisprudencia. Sin embargo, en los primeros fallos en torno a esta, la jurisprudencia se muestra reticente en su aplicación. Pues bien, la reformalización afecta el objeto del proceso, pues la descripción inicial de los hechos en la formalización es una garantía en defensa del imputado.

Así las cosas, posiblemente la único que da sentido a los propósitos de la reformalización es precisar los hechos de la investigación para la defensa. Sin embargo, una imprecisión de los hechos permite recurrir con posterioridad a la nulidad de la sentencia, lo cual, ciertamente, facilita la defensa. De este modo, la imprecisión en relato de los hechos opera en favor del imputado.

33 Sentencia de la Corte de Apelaciones de Santiago Rol 738-2006 del 23 mayo de 2006 (RUC 0500234342-K). 
Como se puede observar, la reformalización no es admisible gracias a un espacio en la legislación o si, por el contrario, se creía preferible contar con esta figura para subsanar omisiones del Ministerio Público. Si bien en la actualidad no se perciben dificultades para aceptar la reformalización, la excepción podría radicar en un argumento procesal. Pues bien, "si fuese ad-portas del vencimiento del plazo de investigación o con cierre de la misma, podría afectar seriamente el derecho de defensa al agregar nuevos hechos no considerados primitivamente" ${ }^{34}$.

Como sea, lo que es claro es que el legislador optó por un modelo orientado a respetar las garantías del debido proceso. Esto es, a través de uno de sus pilares de la comunicación: la formalización. Así, una de las primeras sentencias en la materia es una resolución del Juzgado de Garantía de los Andes. Esta sentencia se opuso a la aplicación de la reformalización, pues la reformalización únicamente se utilizan para solventar las acciones de la fiscalía y crea incertidumbre en relación con los hechos que son imputados en el proceso ${ }^{35}$.

También el fallo del Juzgado de Garantía de los Andes se encuentra en línea con la sentencia del Juzgado de Garantía de San Javier. Este último sostuvo, respecto de la reformalización, su improcedencia, porque el derecho procesal debe ajustarse a los parámetros positivos del ordenamiento chileno ${ }^{36}$. Por último, la sentencia del Juzgado de Garantía de Talca reafirma la tesis de rechazo a la reformalización. Este Juzgado rechazó la reformalización —en la línea del Juzgado de Talcapor no estar presente en la regulación del sistema procesal. Así, en la formalización inicial - en el caso del Juzgado de Talca- se imputó al agente participación como autor en un delito de robo con violencia. Sin embargo, "semanas después el ente persecutor procedió a reformalizar la investigación modificando el día, la hora, el número de sujetos activos y

34 ESCOBAR SALAS, Juan Manuel. La reformalización de la investigación: un problema jurídico no resuelto. 2013, p. 76.

35 Sentencia del Juzgado de Garantía de Los Andes, RIT 251-2004, del 1 junio 2004.

36 Sentencia del Tribunal de Garantía de San Javier, RIT 696-2004, del 30 noviembre 2004. 
demás antecedentes" ${ }^{37}$. La reformalización permitió únicamente precisar los términos de la formalización.

\subsection{INICIATIVAS POSTERIORES DE APLICACIÓN}

A propósito del fallo de la Corte de Apelaciones de Santiago, del 23 de mayo de 2006, un grupo de sentencias, que en principio únicamente aspiraba a introducir modificaciones menores en la relación circunstanciada de los hechos, impuso en el seno de la jurisprudencia la reformalización. El fundamento de estas era una mirada sistemática centrada en el momento procesal oportuno para presentación de nuevos hechos, lo que se expresó en una serie de adaptaciones a la formalización.

Confirmando la idea anteriormente expuesta, la Sentencia del caso Bombas, mediante sentencia del Octavo Juzgado de Garantía de Santiago, en causa Rit 3418-2007, presenta los nuevos hechos en el proceso que, junto con aportar una nueva calificación jurídica de los mismos, se hizo cargo de nuevos presupuestos fácticos ausentes en la formalización inicial ${ }^{38}$. Así, en un inicio se les formalizó a los imputados por el delito de asociación ilícita. Luego, por la figura delictiva de colocación de artefactos explosivos en diferentes partes de Santiago el 2010 ${ }^{39}$. En esta línea, el año 2011, el Ministerio Público requirió una audiencia de reformalización con el objetivo de agregar nuevos hechos y precisar los expuestos en la formalización ${ }^{40}$.

37 ESCOBAR SALAS, Juan Manuel. La reformalización de la investigación: un problema jurídico no resuelto. 2013, p. 44.

38 Sentencia del Octavo Juzgado de Garantía de Santiago, RIT 3418-2007, del 18 de marzo de 2012.

39 Esto, a propósito de la Ley $\mathrm{N}^{\circ} 18.314$ (sobre conductas terroristas) publicada el 17-05-1984.

40 Por último, en este caso uno de los argumentos que sustentó el Ministerio Público radicó que "un juez de garantía no puede negarse a que el ente persecutor realice nuevas formalizaciones de investigación respecto de un imputado”, ESCOBAR SALAS, Juan Manuel. La reformalización de la investigación: un problema jurídico no resuelto. 2013, p. 53. Ello, según el razonamiento de la Sentencia de la Corte Apelaciones de Coyhaique, Rit 372-2004, passim. 
Por otra parte, en lo que al uso de la reformalización respecta, la sentencia del Séptimo Juzgado de Garantía de Santiago, en causa RIT 16.027-10, del 04 abril 2011, no contiene innovación alguna. Según la sentencia, la reformalización permite incorporar nuevos hechos para una mejor defensa. En este caso, la Fiscalía asumió inicialmente una tesis de parricidio que, no obstante, modificó en la reformalización, agregando las figuras penales contempladas en los artículos 399 (lesiones menos graves) y $494 \mathrm{~N}^{\circ} 5$ (agravante en supuestos de violencia intrafamiliar) del Código Penal. Para hacerse cargo de estas figuras, el Juzgado de Garantía de Santiago señaló que una de las finalidades del sistema es entregar a la Fiscalía las herramientas adecuadas para desarrollar su investigación. De ahí que no exista una norma que exija en una sola oportunidad formalizar todos los delitos que se han investigado. Con ello, el Juzgado rechazó la petición de impugnación de la reformalización por parte de la defensa.

También la reformalización es aceptada en el caso La Polar ${ }^{41}$. De un modo diferente a los expuesto con anterioridad, la Fiscalía no incorporó nuevos hechos en el contexto de los presupuestos fácticos, así como en la subsunción de los hechos bajo los supuestos que contempla el art. 160 de la Ley General de Banco, entre otros ilícitos de los que imputó en la formalización. En este sentido, solo especifica los hechos que fueron enunciados en un inicio en la formalización. De ahí que, si bien el Ministerio Público no introduce nuevos hechos en la reformalización, por su especificación, debería considerarse, siguiendo a Escobar, que "se ha comunicado a los imputados el delito por el cual se los investiga dando cumplimiento, de esa forma, a los objetivos de garantía que dicha actuación persigue [...] ha reformalizado buscando precisar y detallar de la mejor manera la forma como se han producido las infracciones" ${ }^{2}$.

Con todo, nos parece que toda imprecisión en la imputación es un argumento que la defensa puede argüir en una audiencia e incluso precisar - de ser necesario alguna convención- en la audiencia de control de detención. Sin embargo, hasta la fecha no se ha presentado

${ }^{41}$ Segundo Juzgado de Garantía de Santiago, en causa RIT 6930-2011, de fecha 14 febrero 2012.

${ }^{42}$ ESCOBAR SALAS, Juan Manuel. La reformalización de la investigación: un problema jurídico no resuelto. 2013, p. 59. 
posiciones dogmáticas en favor de esta interpretación. Como se observa, las primeras sentencias en torno a la reformalización se inscribían en una interpretación restrictiva de las disposiciones del CPP. Pues bien, la imprecisión fáctica era un argumento en resguardo de las garantías del imputado para interponer la nulidad.

\subsection{Parámetros constitucionales}

Si bien los argumentos para cuestionar la reformalización podrían ser diversos, básicamente presentamos dos a nivel constitucional. Por una parte, el primero sería detectar qué hechos se deben incorporar antes dela audiencia de preparación de juicio oral, haciéndose cargo de sus singularidades en aras del debido proceso. Una segunda vía sería más bien positiva, pues la constitución indica en art. $19 \mathrm{~N}^{\circ} 3$, inc. 6 , que toda sentencia de un órgano que ejerza jurisdicción debe fundarse en un proceso previo legalmente tramitado. Ciertamente, la disposición también indica que corresponderá al legislador establecer siempre las garantías de un procedimiento.

El derecho chileno no cuenta con una regulación de la reformalización porque es creación de la jurisprudencia. Por ello, la reformalización trasciende los términos del art. 229 del CPP y cubre nuevos presupuestos fácticos. Presupuestos que aparentemente permitirían una defensa más acuciosa. Así, en lo que al uso abusivo de reformalización concierne, particularmente las hipótesis posteriores a la solicitud del cierre de la investigación o ampliación del plazo de investigación son las que generan mayor resonancia en el sistema.

Si bien la reformalización podría sugerir equipara la comunicación que el fiscal efectúa al imputado con todas las comunicaciones que realiza, esta sería una interpretación extensiva. Nuestra opinión, como se ha dicho, decanta por una interpretación estricta ${ }^{43}$. Sobre todo si la reformalización

43 En esta línea, el art. 5 del CPP indica que no se podrá citar, arrestar, detener, someter a prisión preventiva ni aplicar cualquier otra forma de privación o restricción de libertad a ninguna persona, sino en los casos y en la forma señalados por la Constitución y las leyes.__L Las disposiciones de este Código que autorizan la restricción de la libertad o de otros derechos del imputado o del ejercicio de alguna de sus facultades serán interpretadas restrictivamente y no se podrán aplicar por analogía. 
se practica con posterioridad a la solitud del cierre de la investigación, pues sería imposible determinar de dónde previene la incorporación repentina de estos hechos. De ahí que el segundo argumento - a nivel constitucional-se construye a partir del rechazo de una lectura flexible de la formalización. Tal es el caso paradigmático del caso Bombas y, posteriormente, La Polar. En el caso Bombas, a las antiguas previsiones relativas al uso de artefactos explosivos, existentes en el ordenamiento sustantivo del Código Penal chileno, la reformalización agregó nuevos hechos que indicen en el desarrollo del juicio. Esto es, presupuestos fácticos más amplios que, referidos a la problemática del principio de ejecución, dan cuenta de otros lugares en los que fueron colocados artefactos explosivos en Santiago.

Si bien en el caso La Polar se podría indicar que la precisión de los hechos no constituyó un uso abusivo de la reformalización, no existe una disposición específica en el sistema que comprendan su uso solo en favor del imputado. Por ejemplo, el art. 334 del CPP indica que no se podrá incorporar o invocar como medios de prueba ni dar lectura durante el juicio oral, a los registros y demás documentos que dieren cuenta de diligencias o actuaciones realizadas por la policía o el ministerio público. Sin embargo, existen una serie de fallos que permiten solo la lectura de estos documentos cuando sean favorables al imputado. Último razonamiento que sería necesario incorporar en el caso de la reformalización a modo de excepción y no regla general en el sistema.

Ahora bien, en el contexto constitucional, el legislador chileno optó por una interpretación centrada en el respecto de las garantías fundamentales. Pues bien, a través del art. 5 del CPP se plasma la prohibición de analogía en la lectura de las disposiciones del CPP. La reformalización parece cubierta a través de una interpretación analógica del art. 230 del CPP.

Como es fácil de advertir, ambos argumentos de orden constitucional presentan méritos y defectos, pues la reformalización ofrece la posibilidad de precisar hechos para una mejor defensa en juicio, aunque impulsa las dificultades propias de un defecto en el ejercicio de la acción penal según lo dispuesto en el art. 229 y siguiente del CPP.

En suma, prescindir de la reformalización parece más adecuado desde un punto de vista estricto en la interpretación de las reglas 
del proceso, pero, además de la visibilidad de los alcances de nuevas instituciones en el plano jurisprudencial. A continuación, se podrá apreciar cómo estas dos líneas de argumentación han estado presentes en la discusión en torno a la reformalización.

\section{MÉRITOS Y DEFECTOS DE LA REFoRMALIZACIÓN}

En la medida en que la ley no regula el uso de la reformalización, se resuelve su uso a través de una lectura analógica. Sea que la reformalización se use para precisar presupuestos facticos, antes del cierre de la instigación o con posterioridad a esta, en la actualidad no cabe duda de que debe aplicarse en beneficio del imputado, sin perjuicio de los muy defectuosos términos de su concreción en las disposiciones del ordenamiento chileno.

El principal problema que trae consigo la reformalización es la debida presentación de los hechos. De este modo, la reformalización se acentúa como una hipótesis conflictiva que no encuadra con los hechos de la formalización, la acusación y la sentencia. Es lo que podríamos denominar la cuestión del factum en la imputación, pero susceptible de una contingencia que no reduce el sistema.

Las enormes dificultades que ofrece la reformalización se aprecian a propósito de las primeras sentencias que se pronuncian en torno a esta, que se hacen cargo de su rechazo debido a la falta de su positivización en el sistema. Todo ello implica que lo que subyace a la reformalización, conduce a interpretaciones analógicamente extensivas del ordenamiento, al punto de convertir la formalización en una suerte de indeterminación fáctica.

Otra duda que subsistente es si las disposiciones del art. 229 y art. 5 del CPP son compatibles con la reformalización. Si el punto ya es discutible en el ámbito de las primeras etapas del proceso, donde tradicionalmente se ha considerado que los hechos de la formalización llevan la carga de la congruencia, tanto más lo es en donde no se aprecia que los términos positivos del ordenamiento la reconozcan. Por ello, si la reformalización provoca dudas interpretativas, mayores son las incertidumbres que suscita en relación con el principio de congruencia.

Desde luego es importante que, a diferencia de lo que ocurre con las disposiciones de la formalización, el art. 229 del CPP se haga cargo 
expresamente de la reformalización, así como del principio de congruencia en aras del principio de objetividad. Si bien la escueta formulación del art. 229 del CPP es consonante con la facultad privativa de formalización, es decir, en la que los jueces no pueden interrogar a los involucrados en el proceso, recibir pruebas o incluso solicitar la carpeta investigativa de Fiscalía para calificar la formalización ${ }^{44}$, ello no es suficiente para aceptar la reformalización.

En resguardo de la reformalización, parecen quedar excluidos los hechos que afectan el derecho de defensa y, en general, toda superposición estos que afecte el principio de no contradicción. Ciertamente, la incorporación de nuevos hechos debería contar con una aceptación expresa de la defensa. De este modo, la reformalización demanda explicar la necesidad de incorporar nuevos hechos en favor de la defensa.

La reformalización requiere del ente persecutor una explicación. En definitiva, explicar ¿por qué el debido proceso demanda la incorporación de estos nuevos hechos? Así pues, deberíamos preguntarnos ¿qué sucede si la defensa elabora su teoría del caso y esta es afectada por la incorporación de nuevos hechos en la reformalización? La defensa ¿debería trabajar su teoría del caso desde los presupuestos fácticos iniciales o los contemplados en la reformalización? Cuando esta disyuntiva se produce, debemos examinar si es posible admitir la práctica de la reformalización en el sistema.

Ahora bien, la dogmática no ha tratado en extenso la figura de la reformalización, pues no existe regla en el código que la reconozca. Así, la figura de la formalización es la única comunicación que el fiscal realiza, en audiencia de control de detención, en los términos del art. 229 del CPP. La formalización, como facultad privativa del Ministerio Público, cumple una función de garantía, porque informa

44 En este contexto, siguiendo a Piedrabuena, "en la III Región, un juez le ordenó al fiscal, antes de citar a una audiencia de formalización, que le acompañara la carpeta investigativa para analizar su mérito y como el fiscal se negó, el juez ordenó su detención, siendo el recurso de amparo acogido por la Corte de Copiapó... En un juzgado periférico de Santiago, los jueces interrogaban a las policías y hacían una especie de reconocimiento del imputado por la víctima, situándolos en distintas filas del público asistente”, véase GUILLERMO PIEDRABUENA, Richard. 2011, p. 110. 
al imputado de los hechos en los que se le atribuye participación y su calificación jurídica. ${ }^{45}$

Sin embargo, la inviolabilidad de la defensa conlleva el respecto del principio de congruencia en la reformalización. Si bien el principio regularmente se le simplifica mediante una relación fáctica entre los hechos de la acusación y la sentencia, ciertamente el principio es más amplio. Pues bien, desde que tal relación se origina la demarcación fáctica para requerir instrucción, informar de los hechos al imputado antes de su declaración, en el auto de procesamiento, en el requerimiento acusatorio que eleva el caso a juicio o el acto a través del cual se dicta sentencia ${ }^{46}$, entre otros, deben indicar de forma precisa cuáles son los supuestos de hecho que van a ser objeto de análisis y garantizar el derecho a defensa. De ahí que la comunicación de estos hechos también materialice las garantías consagradas en el art. 93 del $\mathrm{CPP}^{47}$.

Conforme con lo anterior, como varios de los supuestos de aplicación de la reformalización dicen relación con los motivos de la imputación, el principio de congruencia adquiere relevancia. Por eso, desde que los dogmáticos chilenos renuevan su estudio y exhiben su importancia, las diferenciaciones fundamentales que en él se constatan se debería considerar en la reformalización. El principio de congruencia es una herramienta indispensable en el debate contra aquellas doctrinas que propugnan una correlación exclusiva entre los presupuestos de la acusación y la sentencia, de modo que la determinación de la infracción del principio no penda de un balance entre los hechos de la formalización, la acusación y, posteriormente, la sentencia condenatoria.

45 HORVITZ LENNON, María Inés; LÓPEZ MASLE, Julián. Derecho procesal penal chileno, t.I. Santiago: Editorial jurídica de chile, 2002. p.540

46 JAUCHEN, Eduardo M. Derechos del Imputado. Buenos Aires: Rubinzal-Culzoni Editores, 2014, p.168.

47 En este contexto, en torno a los derechos y garantías del imputado. Todo imputado podrá hacer valer, hasta la terminación del proceso, los derechos y garantías que le confieren las leyes. Así pues, tendrá derecho, según la letra a) del art. 93 del CPP, a que se le informe de manera específica y clara acerca de los hechos que se le imputaren y los derechos que le otorgan la Constitución y las leyes; y, según la letra c) del art. 93 del CPP, a solicitar de los fiscales diligencias de investigación destinadas a desvirtuar las imputaciones que se le formularen. 
Los esfuerzos de la dogmática ponen de manifiesto las diferenciaciones expuestas como la importancia de precisión en los términos de la imputación; esto es, en etapas procesales que inciden, determinantemente, en la formulación de teoría del caso de la defensa. Así, la formalización "es una actuación unilateral, exclusiva y soberana del fiscal que cumple una función esencialmente garantista, que consiste en informar al imputado de manera específica y clara acerca de los hechos que se le atribuyen y su calificación jurídica, esto es, el contenido de la imputación jurídico-penal que se dirige en su contra" ${ }^{48}$.

De este modo, desde la óptica de la defensa, cada imputado tiene derecho a tener conocimiento de los hechos por los cuales se le investiga, es decir, "se asegura que estas personas, que pasan a denominarse imputados, sean debidamente emplazadas o tengan oportuno y debido conocimiento de la incoación del proceso en su contra, dirigido a establecer su posible responsabilidad penal en algún hecho especifico" ${ }^{49}$. Sin embargo, a pesar de que la dogmática sigue tematizando acerca del principio de congruencia, y de la trascendencia que ha adquirido en la formalización, su estudio continúa siendo escasamente desarrollado en lo que compete a la reformalización. Con ello, este artículo reinserta la discusión en el debate académico.

\section{Conclusiones}

La reformalización es una regla no positivizada en el proceso, que provee criterios inadecuados para precisar el objeto del proceso. En consecuencia, sin perjuicio de que esta comprende un espectro que puede ser positivo para el defendido, el sistema procesal se debe ordenar a una interpretación estricta de sus disposiciones. Si bien la reformalización puede ser un instrumento valioso en aras del ejercicio del principio de objetividad, puede prestarse para un uso arbitrario. La reformalización

${ }^{48}$ CERDA SAN MARTÍN, Rodrigo; HERMOSILLA IRIARTE, Francisco. El Código Procesal Penal, Comentarios, Concordancias y Jurisprudencia. Santiago: Librotecnia, 2006, p. 266.

49 CAROCCA PÉREZ, Alex. La defensa penal pública. Santiago: Lexis Nexis, 2002, p.73 
solo puede ser reconocida en el sistema de ser favorable al imputado, puesto que, confrontado con el principio de congruencia, esta únicamente debe aportar soluciones consistentes en la presentación precisa de los hechos investigados.

\section{Bibliografía}

ARIAS VICENCIO, Cristián. El artículo 360 del Código procesal penal. Revista de Estudios de la Justicia, Santiago, n. 9, p. 151-174, 2007. https://doi. org/10.5354/0718-4735.2007.15118

AGUIRREZABAL GRÜNSTEIN, Maite, "La congruencia procesal como límite del principio dispositivo en el proceso civil", en Arancibia, Jaime (editor), La buena fe en el Derecho. Estudios en homenaje a los treinta años de la Facultad de Derecho de la Universidad de los Andes (Chile) 1990/2020. Valencia: Tirant lo Blanch, 2020.

BINDER, Alberto M. Introducción al Derecho Procesal Penal. Buenos Aires: Editorial Ad-hoc, 1999.

BLANCO SUÁREZ, Rafel. Código Procesal Penal: Sistematizado con jurisprudencia. Santiago: Thomson Reuters, 2017.

BLANCO, Rafael; DECAP, Mauricio; MORENO, Leonardo; ROJAS, Hugo. Litigación estratégica en el nuevo proceso penal. Santiago: LexisNexis, 2005.

CAROCCA PÉREZ, Alex. Congruencia entre Acusación y Defensa en el Nuevo Proceso Penal Chileno. Cuadernos de Análisis Jurídico Universidad Diego Portales, Santiago, n. 39, p. 310, 1998.

CERDA, Rodrigo; HERMOSILLA, Francisco. El Código Procesal Penal. Comentario, concordancias y jurisprudencia. Santiago: Librotecnia, 2006.

DEL RÍO FERRETTI, Carlos. Los poderes de resolución y calificación jurídica en la doctrina jurisprudencial del tribunal europeo de derechos humanos paralelismos con la situación chilena. Revista de Derecho, Valdivia, v. 22, n. 1, p. 203-233, 2009. http://dx.doi.org/10.4067/S0718-09502009000100010

DEL RÍO FERRETTI, Carlos. Los poderes de decisión del juez penal: Principio acusatorio y determinadas garantías procesales (el deber de correlación). Santiago: Editorial Jurídica de Chile, 2009.

ESCOBAR SALAS, Juan Manuel. La reformalización de la investigación: un problema jurídico no resuelto. Disponible en: <http://repositorio.uchile.cl/ handle/2250/114379>. Último acceso: 13 dic. 2020. 
FALCONE SALAS, Diego. Apuntes sobre la formalización de la investigación desde la perspectiva del objeto del proceso penal. Revista de Derecho Universidad Católica del Norte Sección, Estudios Año 21 - No 2, pp. 183-224, 2014. http:// dx.doi.org/10.4067/S0718-97532014000200006

FLEMING, Abel; LÓPEZ VIÑALS, Pablo. Garantías del Imputado. Buenos Aires: Rubinzal Culzoni, 2007.

GANDULFO, R. Eduardo. Principios del derecho procesal penal en el nuevo sistema de procedimiento chileno. Revista de Derecho de la Universidad Católica de Valparaíso. Valparaíso, n. 20, p 415-474, 1999. http://dx.doi.org/10.4151/ ISSN.07186851-Vol.0-Num.20-Fulltext.448

GUERRA, Rodrigo. Estado de necesidad como conflicto de intereses: una propuesta de interpretación desde la inevitabilidad. Santiago: Ara Editores, 2017.

GUILLERMO PIEDRABUENA, Richard. La formalización de la investigación, la decisión de no perseverar y el forzamiento de la acusación, en relación a los derechos de la víctima querellante. Revista de Derecho, Santiago, n. 26, p. 109136, 2011.

GUILLERMO PIEDRABUENA, Richard. Memorias del Primer Fiscal Nacional. Santiago: Editorial Thomson Reuters, 2011.

HORACIO LANGEVIN, Julián. Nuevas Formulaciones del Principio de Congruencia: Correlación entre Acusación, Defensa y Sentencia. Buenos Aires: Fabián J. Di Plácido Editor, 2007.

HORVITZ LENNON, María Inés; López Masle, Julián. Derecho Procesal Penal chileno. Santiago: Editorial Jurídica de Chile, 2002.

HRUSCHKA, Joachim. Imputación y Derecho penal: Estudios sobre la teoría de la imputación. Navarra: Editorial Aranzadi, 2005.

HRUSCHKA, Joachim. La imputación ordinaria y extraordinaria en Pufendorf. Bogotá: Universidad del Externado de Colombia, 2006.

JAUCHEN, Eduardo M. Derechos del Imputado. Buenos Aires: Rubinzal Culzoni Editores, 2014.

MAIER, Julio. Derecho Procesal Penal Tomo I Fundamentos. Buenos Aires: Editores del Puerto S.R.L, 2004.

MORENO HOLMAN, Leonardo. Teoría del caso. Buenos Aires: Ediciones Didot, 2014. 
ROXIN, Claus. Derecho procesal penal. Buenos Aires: Editores del Puerto, 2001.

RODRÍGUEZ VEGA, Manuel. Sistema acusatorio de justicia penal y principio de obligatoriedad de la acción penal, Revista de Derecho de la Pontificia Universidad Católica de Valparaíso XL (Valparaíso, Chile, 2013, 1er Semestre) pp. 643 - 686, 2013. http://dx.doi.org/10.4067/S0718-68512013000100020

SÁNCHEZ-OSTIZ, Pablo. Fundamentos de Política criminal: Un retorno a los principios. Madrid: Marcial Pons, 2012.

SÁNCHEZ-OSTIZ, Pablo. La libertad del Derecho penal: Estudios sobre la doctrina de la imputación. Barcelona: Atelier, 2014.

SANCINETTI, Marcelo Alberto. El disvalor de acción como fundamento de una dogmática jurídico-penal racional. InDret Penal, Barcelona, n. 2, p 1-21, 2017.

SILVA SÁNCHEZ, Jesús María. Perspectivas sobre la política criminal moderna. Buenos Aires: Editorial Ábaco de Rodolfo Depalma, 1998.

TARUFFO, Michele. La Prueba. Madrid: Marcial Pons, 2008.

\section{Additional information and author's declarations (scientific integrity)}

Conflict of interest declaration: the author confirms that there are no conflicts of interest in conducting this research and writing this article.

Declaration of authorship: all and only researchers who comply the authorship requirements of this article are listed as authors; all coauthors are fully responsible for this work in its entirety.

Declaration of originality: the author assures that the text here published has not been previously published in any other resource and that future republication will only take place with the express indication of the reference of this original publication; he also attests that there is no third party plagiarism or self-plagiarism. 


\section{Editorial process dates}

(http://www.ibraspp.com.br/revista/index.php/RBDPP/about/editorialPolicies)

- Submission: 03/05/2021

- Desk review and plagiarism check: 23/05/2021

- Review 1: 03/06/2021

- Review 2: 22/06/2021

- Preliminary editorial decision: $17 / 08 / 2021$

- Correction round return: 23/08/2021

- Final editorial decision: 15/09/2021

\section{Editorial team}

- Editor-in-chief: 1 (VGV)

- Assistant-editor: 1 (PM)

- Reviewers: 2

\section{HOW TO CITE (ABNT BRAZIL):}

GUERRA ESPINOSA, Rodrigo Andrés. Reformalización en la mira de la congruencia. Revista Brasileira de Direito Processual Penal, vol. 7, n. 3, p. 2127-2154, set./dez. 2021. https://doi.org/10.22197/rbdpp.v7i3.559

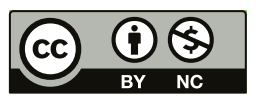

Esta obra está licenciada com uma Licença Creative Commons Atribuição-NãoComercial 4.0 Internacional. 